\title{
UJI EMPIRIS HUBUNGAN ANTARA TATA KELOLA PERUSAHAAN DAN PENGUNGKAPAN RISIKO
}

\author{
Arfan Amrin*1, Abid Ramadhan ${ }^{2}$ \\ ${ }^{1,2}$ Universitas Muhammadiyah Palopo; Jl. Jend Sudirman km 3 Binturu, Palopo \\ E-mail: *1arfan_amrin@umpalopo.ac.id, ${ }^{2}$ abidramadhan8@gmail.com
}

\begin{abstract}
Abstrak
Penelitian ini bertujuan untuk menguji hubungan antara tata kelola perusahaan dan pengungkapan risiko perusahaan. Tata kelola perusahaan dalam penelitian ini diproksikan dengan frekuensi pertemuan komite audit, keberadaan komite pemantau risiko, dan kualitas auditor eksternal. Populasi dalam penelitian ini adalah perusahaan nonkeuangan yang terdaftar di Bursa Efek Indonesia tahun 2017. Purposive sampling digunakan dengan total sampel sebanyak 352 perusahaan nonkeuangan memenuhi kriteria-kriteria yang telah ditetapkan. Metode analisis data yang digunakan adalah analisis regresi linier berganda. Variabel tata kelola perusahaan dalam model penelitian ini hanya mampu menjelaskan sebesar $11,30 \%$ variabel pengungkapan risiko. Hasil empiris dalam penelitian ini menunjukkan bahwa semua variabel tata kelola perusahaan meliputi frekuensi pertemuan komite audit, keberadaan komite pemantau risiko, dan kualitas auditor eksternal berhubungan signifikan dengan pengungkapan risiko perusahaan.
\end{abstract}

Kata Kunci: Tata kelola perusahaan, nonkeuangan, pengungkapan risiko

\begin{abstract}
The purpose of this study is to test the relationship between corporate governance and corporate risk disclosure. The corporate governance in this study was proscribed with the frequency of audit committee meetings, the existence of risk monitoring committees, and the quality of external auditors. The population in this study is all non-financial company listed on the Indonesia stock Exchange in 2017. Purposive sampling used in this study with a total sample of 352 nonfinancial companies that comply predetermined criterias. The data analysis method used is a double linear regression analysis. The corporate governance variable in the study model is only able to describe $11.30 \%$ of risk disclosure variables. The empirical results in this study show that all corporate governance variables include the frequency of audit committee meetings, the existence of risk monitoring committees, and the quality of external auditors are significantly related to corporate risk disclosure.
\end{abstract}

Keywords: corporate governance, nonfinancial, risk disclosure

\section{PENDAHULUAN}

Keberadaaan risiko dalam setiap perusahaan menjadi informasi penting bagi para pihak yang berkepentingan. Pengungkapan risiko dalam perusahaan merupakan salah satu bagian penting bagi perusahaan yang melakukan manajemen risiko. Informasi risiko sangat dibutuhkan untuk menghindari atau mengantisipasi terjadinya praktik kecurangan akuntansi. Banyaknya kasus kecurangan akuntansi yang terjadi selama ini menyebabkan investor sebagai pihak yang berkepentingan semakin ragu atas penyampaian informasi yang dilakukan oleh perusahaan. Contoh yang dapat kita lihat adalah kasus kecurangan perusahaan besar seperti Enron dan Worldcom (Oorschot dalam Suhardjanto, 2011). Semakin kompleks risiko yang dihadapi 
perusahaan dalam setiap kegiatannya akan menimbulkan respon untuk mencegah, menghindari, atau mengurangi. Namun, perlu diperhatikan bahwa untuk melakukan hal tersebut, perusahaan harus mampu melakukan pengelolaan yang baik terhadap risikorisiko dalam rangka mengurangi terjadinya kerugian. Manajemen risiko perusahaan yang baik tentunya dapat memberikan manfaat yang baik bagi perusahaan serta mampu meminimalisir risiko sehingga dapat menghindari terjadinya kerugian sebagai akibat dari adanya risiko.

Perusahaan dalam upaya tetap tumbuh dan berkembang dihadapkan pada transparansi mengungkapkan atau menyampaikan informasi perusahaan agar dapat membantu para pengambil keputusan termasuk keputusan oleh pihak investor dalam mengantisipasi kecenderungan perubahan kondisi. Pengungkapan informasi perusahaan terangkum dalam laporan keuangan. Oleh karena itu, informasi yang disampaikan harus relevan, tepat waktu, dan bernilai. Pengungkapan informasi secara jujur dan terbuka dalam semua hal dapat mempengaruhi kepercayaan pengguna informasi terhadap kinerja manajemen suatu perusahaan.

Teori agensi menyatakan apabila terdapat pemisahan antara pemilik sebagai prinsipal dan manajer sebagai agen, maka akan muncul permasalahan agensi karena masing-masing pihak tersebut akan selalu berusaha untuk memaksimalkan fungsi utilitasnya (Jensen dan Meckling, 1976). Implikasi atas pendelegasian ini tentu saja agen dihadapkan pada kemampuan dalam mempertanggungjawabkan aktivitasnya kepada prinsipal. Teori agensi dalam implementasi pengungkapan risiko mampu menjelaskan penyampaian informasi yang reliabel tentang risiko oleh manajer terhadap pihak pengguna informasi akuntansi. Adanya informasi yang reliabel mengenai risiko oleh manajer kepada pemegang saham dan kreditur akan mengurangi masalah asimetri informasi (Elzahar dan Hussainey, 2016).

Informasi risiko juga merupakan bagian penting dalam perusahaan untuk mengevaluasi kemungkinan risiko yang akan terjadi (Abraham dan Cox, 2007; Miihkinen, 2013). Adanya peningkatan kebutuhan informasi risiko telah memotivasi peneliti sebelumnya untuk menguji hubungan antara tata kelola perusahaan dan pengungkapan risiko. Tata kelola merupakan salah satu faktor yang dianggap dapat mempengaruhi pengungkapan risiko suatu perusahaan. Al-Maghzom et al. (2016) menyatakan bahwa komite audit merupakan elemen penting dari sistem kontrol internal dalam tata kelola suatu perusahaan.

Beberapa penelitian terdahulu menunjukkan bahwa frekuensi pertemuan komite audit memiliki pengaruh signifikan terhadap tingkat pengungkapan (Li et al., 2008; Ettredge et al., 2011; Taliyang dan Jusop, 2011; Li et al., 2012; Allegrini dan Greco, 2013; Talpur et al., 2018). Peneliti lainnya (Al-Maghzom et al., 2016) juga menunjukkan bahwa salah satu faktor yang dapat menyebabkan munculnya motivasi bank dalam mengungkapkan informasi risiko adalah banyaknya rapat yang diselenggarakan oleh komite audit.

Faktor lain yang dianggap dapat mempengaruhi pengungkapan risiko adalah keberadaan komite pemantau risiko. Keberadaan komite atau badan pemantau risiko dalam perusahaan dapat lebih efektif mengevaluasi pengawasan internal serta memastikan bahwa pengelolaan memenuhi aturan dan hukum yang berlaku. Hasil penelitian (Meizaroh dan Lucyanda, 2011) menunjukkan bahwa keberadaan komite pengelola risiko berhubungan signifikan 
dengan pengungkapan risiko perusahan dan memiliki efek yang signifikan terhadap risk management disclosure (Buckby et al., 2015). Selain itu, kualitas audit perusahaan perlu juga diperhatikan dalam melakukan proses pengauditan yang dapat mempengaruhi kepatuhan pengungkapan perusahaan (Ettredge et al., 2011). Penunjukkan auditor menjadi sinyal bagi investor dalam menilai kualitas pengungkapan perusahaan. Kualitas audit seringkali dilihat dari reputasi auditor. Beberepa temuan terdahulu menunjukkan bahwa jenis auditor berhubungan signifikan dengan pengungkapan risiko (Lopes dan Rodrigues, 2007; Oliveira et al., 2011; Mokhtar dan Mellett, 2013; Abid dan Shaiq, 2015; Elshandidy dan Neri, 2015; Carmona et al., 2016); tidak signifikan (Al-Mutawaa dan Hewaidy, 2010) dengan pengungkapan.

Penelitian ini menguji hubungan antara tata kelola perusahaan dan pengungkapan risiko. Model risiko dalam penelitian ini mengacu pada model yang dikembangkan oleh Institute of Chartered Accountants in England dan Wales (ICAEW) yang juga digunakan oleh para peneliti sebelumnya (Miihkinen, 2013; Mokhtar dan Mellett, 2013). Beberapa peneliti sebelumnya telah menguji hubungan antara tata kelola perusahaan dan pengungkapan risiko. Namun, hasil penelitian yang dilakukan masih bervariasi. Selain itu, pembentukan komite pemantau risiko diwajibkan hanya pada sektor keuangan saja. Terlepas dari pembentukan komite pemantau risiko yang diwajibkan, seharusnya perusahaan lain juga menyadari bahwa keberadaan komite ini begitu esensial untuk mengelola manajemen risiko suatu perusahaan. Perusahaan juga dalam kegiatannya tentu memiliki dan menghadapi risiko yang berbeda sehingga pengungkapan informasi risiko juga cenderung berbeda.
Berangkat dari masalah dan inkonsistensi temuan sebelumya, peneliti ingin mengisi kekosongan tersebut. Kontribusi dari penelitian ini memberikan manfaat secara teoritis sebagai literatur dalam menjelaskan hubungan antara tata kelola perusahaan dan pengungkapan risiko perusahaan. Kontribusi teoritis lainnya dapat memberikan ide atau gagasan bagi akademisi untuk melakukan penelitian selanjutnya mengenai pengungkapan risiko perusahaan. Kontribusi kebijakan dalam penelitian ini adalah bagi pengguna informasi akuntansi dapat dijadikan sebagai bahan pertimbangan dalam pengambilan keputusan investasi ataupun pemberian kredit kepada perusahaan khususnya yang melakukan pelaporan risiko. Kontribusi bagi manajemen perusahaan dapat dijadikan sebagai informasi untuk mengimplementasikan tata kelola perusahaan yang baik.

\section{METODE PENELITIAN}

Data dalam penelitian ini dikumpulkan melalui laporan tahunan perusahaan nonkeuangan yang terdaftar di Bursa Efek Indonesia periode 2017. Jumlah perusahaan nonkeuangan yang terdaftar hingga akhir periode 2017 sebanyak 474 perusahaan. Metode pengambilan sampel dalam penelitian ini menggunakan purposive sampling dengan kriteria yang telah ditetapkan meliputi perusahaan nonkeuangan yang terdaftar di Bursa Efek Indonesia periode 2017, mempublikasikan laporan tahunan periode 2017, tahun buku dalam laporan tahunan berakhir tanggal 31 Desember, dan laporan tahunan memiliki kelengkapan data yang dibutuhkan. Sebanyak 352 perusahaan nonkeuangan memenuhi kriteria dalam penelitian ini. Indeks pengungkapan risiko yang digunakan dalam penelitian ini mengacu 
pada penggunaan model modifikasian yang dikembangkan oleh Institute of Chartered Accountants in England and Wales (ICAEW) yang juga digunakan oleh peneliti sebelumnya (Miihkinen, 2013; Mokhtar dan Mellett, 2013). Pengungkapan dikategorikan menjadi risiko finansial, risiko operasional, risiko pemberdayaan, risiko pemrosesan teknologi dan informasi, risiko integritas, dan risiko strategis dengan total item 40 (lihat tabel 1).

Table 1 Item Pengungkapan Risiko

\begin{tabular}{l} 
Risiko finansial \\
1. Komoditi \\
2. Kelangsungan hidup \\
3. Biaya modal \\
Risiko operasional \\
4. Kepuasan pelanggan \\
5. Pengembangan produk \\
6. Efisiensi dan kinerja \\
7. Sumber \\
8. Persediaan using \\
9. Kegagalan produk dan layanan \\
10. Lingkungan \\
11. Kesehatan dan keselamatan \\
12. Erosi nama merek \\
13. Proses manajemen \\
14. Fluktuasi harga faktor-faktor produksi \\
15. Gangguan rantai pasokan \\
Risiko pemberdayaan \\
16. Kepeminimpinan dan manajemen \\
17. Outsourcing \\
18. Insentif kinerja \\
19. Kesediaan dalam perubahan \\
20. Komunikasi \\
Risiko proses informasi dan teknologi \\
21. Intergritas \\
22. Akses \\
23. Ketersediaan \\
24. Infrastruktur \\
Risiko integritas \\
25. Kecurangan manajemen dan pegawai \\
26. Tindakan illegal \\
27. Reputasi \\
28. Kebijakan manajemen \\
29. Organisasi manajemen \\
Risiko strategi \\
30. Pemindaian lingkungan \\
31. Industri \\
32. Portofolio bisnis \\
33. Pesaing \\
\hline
\end{tabular}

34. Penetapan harga

35. Penilaian

36. Perencanaan

37. Siklus hidup

38. Pengukuran kinerja

39. Regulasi

40. Kekuasaan dan politik

Sumber: Miihkinen, 2013; Mokhtar dan Mellett, 2013; Amrin, 2019

Persamaan indeks pengungkapan risiko adalah sebagai berikut:

$I P R=\frac{\text { Pengungkapan risiko yang dilakukan }}{\text { Total item pengungkapan risiko }}$ Pengungkapan menggunakan metode skoring (Amran et al., 2009) dengan skor 1 untuk tiap pengungkapan item dan 0 jika tidak diungkapkan. Frekuensi pertemuan komite audit diukur dengan melihat berapa jumlah pertemuan atau rapat yang dilakukan selama setahun dan komite pemantau risiko diukur dengan dummy 1 untuk perusahaan yang memiliki komite pemantau pemantu risiko dan 0 jika tidak. Metode analisis data yang digunakan dalam penelitian ini adalah analisis statistik regresi linier berganda. Pengujian hipotesis dilakukan setelah memenuhi asumsi klasik. Adapun model regresi diformulasikan dengan persamaan berikut:

$I P R=\beta_{0}+\beta_{1} P K A+\beta_{2} K P R+\beta_{3} K A E+\varepsilon$

dimana IPR adalah indeks pengungkapan risiko perusahaan; PKA adalah frekuensi pertemuan komite audit; KPR adalah ketersediaan komite pemantauan risiko; dan KAE adalah kualitas auditor eksternal.

\section{HASIL DAN PEMBAHASAN}

Hasil analisis statistik deskriptif terangkum pada tabel 2 menunjukkan bahwa perusahaan nonkeuangan yang terdiri dari 352 memiliki rata-rata 
sebesar 0,21 atau 21\%. Nilai tersebut mengindikasikan bahwa perusahaan nonkeuangan dalam penelitian ini masih memiliki kesadaran yang rendah untuk mengungkapkan risikonya. Hal ini kemungkinan karena pengungkapan yang masih bersifat sukarela. Berdasarkan tabel 3, rata-rata frekuensi pertemuan komite audit perusahaan adalah 7 kali. Tabel 4 menunjukkan bahwa perusahaan yang memiliki komite pemantau risiko sebesar $15,90 \%$ dan yang tidak memiliki komite pemantau risiko sebesar $84,10 \%$. Komposisi perusahaan dengan jenis auditor terafiliasi big four sebesar 38,40\% dan jenis auditor terafiliasi selain big four sebesar 61,60\%. Hasil uji hipotesis dalam penelitian ini terangkum dalam tabel 5.

Tabel 2 Statistik Deskriptif Pengungkapan Risiko

\begin{tabular}{cccccc}
\hline Variabel & N & Mean & Max & Min & $\begin{array}{c}\text { Std. } \\
\text { Deviation }\end{array}$ \\
\hline IPR & 352 & 0,21 & 0,75 & 0,03 & 0,11 \\
\hline
\end{tabular}

Sumber: Hasil olah data.

Notes: IPR adalah indeks pengungkapan risiko perusahaan

Tabel 3 Statistik Deskriptif Variabel Independen

\begin{tabular}{cccccc}
\hline Variabel & $\mathbf{N}$ & Mean & Max & Min & Std. Deviation \\
\hline PKA & 352 & 6,71 & 75,00 & 0,00 & 6,62 \\
\hline
\end{tabular}

Sumber: Hasil olah data.

Notes: PKA adalah frekuensi pertemuan komite audit.

Tabel 4 Statistik Deskriptif Variabel Independen

\begin{tabular}{lc}
\hline \multicolumn{1}{c}{ Variabel } & Persentase Perusahaan Sampel \\
\hline Komite pemantau/manajemen risiko (KPR): & 15,90 \\
1. Ada & 84,10 \\
2. Tidak Ada & \\
\hline Kualitas auditor eksternal (KAE): & 38,40 \\
1. Terafiliasi Big Four & 61,60 \\
2. Lainnya &
\end{tabular}

Sumber: Hasil olah data

Notes: KPR adalah keberadaan komite pemantau risiko yang diukur dengan teknik dummy (1 untuk perusahaan yang memiliki komite pemantau risiko dalam perusahaan dan 0 jika tidak); KAE adalah kualitas auditor eksternal yang diukur dengan dummy 1 bila perusahaan yang diamati diaudit oleh KAP yang berafiliasi dengan KAP internasional (Big Four Accounting) dan 0 jika lainnya.

Tabel 5 Statistik Deskriptif Variabel Independen

\begin{tabular}{ccccc}
\hline \multirow{2}{*}{ Variabel } & \multirow{2}{*}{ Prediksi } & \multicolumn{2}{c}{ Model (IPR) } & \multirow{2}{*}{ Kesimpulan } \\
\cline { 3 - 4 } & & Koefisien & Signifikansi & \\
Konstanta & + & 0,169 & 0,000 & \\
PKA & + & 0,002 & $0,018^{*}$ & Terdukung \\
KPR & + & 0,076 & $0,000^{* *}$ & Terdukung \\
KAE & Adjusted $R^{2}=0,113$ & $F$ Value $=19,478$ & $F$ Significant $=0,000$ & $N=352$ \\
\hline$R^{2}=0,120$ & A* Signifikan pada level 0,01 dan $*$ Signifikan pada level 0,05 & &
\end{tabular}


Notes: IPR adalah indeks pengungkapan risiko perusahaan; PKA adalah frekuensi pertemuan komite audit; KPR adalah keberadaan komite pemantau risiko yang diukur dengan teknik dummy (1 untuk perusahaan yang memiliki komite pemantau risiko dalam perusahaan dan 0 jika tidak); KAE adalah kualitas auditor eksternal yang diukur dengan dummy 1 bila perusahaan yang diamati diaudit oleh KAP yang berafiliasi dengan KAP internasional (Big Four Accounting) dan 0 jika lainnya.

\section{Frekuensi Pertemuan Komite Audit dan Pengungkapan Risiko}

Variabel frekuensi rapat komite audit (PKA) pada tabel 5 menujukkan hasil yang berhubungan positif dan signifikan dengan pengungkapan risiko (H1 terdukung). Hasil penelitian ini sejalan dengan Li et al. (2008, 2012); Taliyang et al. (2011); Allegrini dan Greco (2013); Al-Maghzom et al. (2016); dan Talpur et al. (2018). Hal ini mengindikasikan bahwa pelaksanaan rapat oleh komite audit perusahaan dapat membantu anggota komite untuk saling bertukar informasi termasuk informasi risiko perusahaan sehingga memungkinkan melakukan identifikasi serta meminimalisasinya. Semakin rutin komite audit melakukan pertemuan, pengungkapan informasi perusahaan juga semakin transparan, termasuk mengenai informasi risiko perusahaan. Selain itu, hasil penelitian ini juga bertentangan dengan pernyataan Menon dan Williams (1994) bahwa jumlah pertemuan komite audit bukan merupakan indikator komite audit dalam menjalankan tugasnya secara efektif.

\section{Keberadaan Komite Pemantau Risiko dan Pengungkapan Risiko}

Komite pemantauan risiko (KPR) berhubungan positif dan signifikan dengan pengungkapan risiko (H2 terdukung) (lihat tabel 5). Hasil penelitian ini sejalan dengan temuan sebelumnya (Meizaroh dan Lucyanda, 2011; Buckby et al., 2015) yang menemukan bahwa keberadaan komite manajemen risiko berpengaruh positif dan signifikan terhadap pengungkapan risiko perusahaan. Temuan ini mengindikasikan secara empiris bahwa adanya komite pemantauan risiko risiko dalam suatu perusahaan dapat lebih efektif mengevaluasi pengawasan internal terutama mengenai risiko perusahaan. Terciptanya efektivitas ini karena anggota komite pemantau risiko menilai dan menindaklanjuti potensi terjadinya risiko. Temuan ini juga mendukung pernyataan Subramaniam et al. (2009) bahwa salah satu unsur penting dalam pelaksanaan manajemen risiko suatu perusahaan adalah risk management committee. Keberadaan komite pemantauan risiko perusahaan mampu memberikan perhatian terhadap pengawasan risiko.

\section{Kualitas Auditor Eksternal dan Pengungkapan Risiko}

Kualitas auditor eksternal (KAE) berhubungan positif dan signifikan dengan pengungkapan risiko (H3 terdukung) (lihat tabel 5). Hasil penelitian ini sejalan dengan peneliti sebelumnya (Lopes dan Rodrigues, 2007; Oliveira et al., 2011; Mokhtar dan Mellett, 2013; Abid dan Shaiq, 2015; Elshandidy dan Neri 2015; Carmona et al., 2016). Temuan ini berhasil membuktikan bahwa perusahaan yang diaudit oleh auditor eksternal yang berafiliasi dengan big four accounting firm cenderung mengungkapkan risiko yang lebih luas karena mendapat tekanan dari auditor sebagai bentuk dalam menjaga citra atau nama baik. Selain itu, hasil penelitian ini juga menunjukkan bahwa auditor merupakan elemen kunci mekanisme pengawasan eksternal perusahaan yang berperan dalam meningkatkan efektivitas dan 
menciptakan tata kelola yang baik serta mempengaruhi sistem pengawasan internal perusahaan.

Temuan penelitian ini memiliki implikasi untuk regulator, perusahaan, dan investor. Pertama, penting bagi regulator untuk memperhatikan manfaat informasi risiko kepada investor melalui pengungkapan risiko secara terperinci. Pendekatan serupa bisa memberikan solusi yang menjanjikan untuk meningkatkan relevansi pengungkapan risiko kepada investor juga di negara lain. Kedua, perusahaan dapat memanfaatkan hasil penelitian untuk mengurangi asimetri biaya modalnya.

Akhirnya, investor mendapat manfaat dari penelitian melalui peningkatan kesadaran hubungan antara asimetri informasi dan pengungkapan risiko. Sehingga hasilnya dapat membantu mereka mengembangkan perusahaan yang lebih efektif strategi.

\section{KESIMPULAN}

Perusahaan mengungkapkan risiko sebesar 21\%. Angka tersebut mengindikasikan bahwa perusahaan nonkeuangan yang terdiri dari 352 dalam penelitian ini memiliki tingkat kesadaran atas pengungkapan risiko yang masih rendah. Hasil pengujian dalam penelitian ini menunjukkan bahwa semua variabel tata kelola perusahaan yang terdiri dari frekuensi pertemuan komite audit, keberadaan komite pemantau risiko, dan kualitas auditor eksternal berhubungan signifikan dengan pengungkapan risiko perusahaan. Variabel tata kelola perusahaan dalam model penelitian ini hanya mampu menjelaskan sebesar $11,30 \%$ variabel pengungkapan risiko. Selain itu, hasil empiris penelitian ini juga membuktikan bahwa keberadaan komite pemantauan risiko dalam perusahaan merupakan faktor utama untuk meningkatkan pengungkapan risiko perusahaan nonkeuangan.

\section{SARAN}

Penelitian ini memiliki keterbatasan yang tidak dapat dihindari oleh peneliti dan dapat berpengaruh pada hasil penelitian. Periode pengamatan dalam penelitian ini terhitung singkat karena hanya satu tahun sehingga tidak memungkinkan untuk digeneralisasi dengan penelitian yang telah ada. Penelitian selanjutnya akan lebih baik jika menggunakan periode pengamatan yang lebih panjang agar dapat mengetahui hubungan peristiwa khusus terhadap pengungkapan risiko. Kedua, pengambilan keputusan pengungkapan risiko dalam penelitian ini ditentukan atas dasar interpretasi peneliti, sehingga memungkinkan terjadinya perbedaan penilaian karena kondisi subyektifitas. Penelitian selanjutnya sebaiknya dalam proses pengambilan suatu keputusan perlu berdiskusi kepada pakar agar tidak salah dalam interpretasi hasil dan melakukan simulasi sebelum data dikumpulkan agar lebih reliabel. Ketiga, variabel yang digunakan dalam penelitian ini terbatas hanya tata kelola perusahaan yang terdiri dari frekuensi pertemuan komite audit, keberadaan komite pemantau risiko, dan kualitas auditor eksternal. Penelitian selanjutnya dapat menambahkan faktor lain yang dapat mempengaruhi pengungkapan risiko seperti diversitas gender dewan, kepemilikan oleh pemerintahan, dan karakteristik risiko pemantau risiko agar lebih memperkuat model penelitian untuk memprediksi pengungkapan risiko. Keempat, hasil penelitian ini tidak dapat digeneralisasi dan/atau dibandingkan dengan negara lainnya karena menggunakan teknik purposive sampling untuk memastikan eksistensi pengungkapan risiko perusahaan. Penelitian lanjutan dapat menggunakan metode lainnya untuk memastikan keberadaan pengungkapan risiko suatu perusahaan. Kelima, penelitian ini hanya 
fokus pada laporan tahunan perusahaan. Penelitian selanjutnya dapat melakukan pengembangan tidak hanya fokus pada laporan tahunan tapi juga melalui laporan-laporan lainnya yang dapat memberikan informasi seperti laporan interim perusahaan.

\section{DAFTAR PUSTAKA}

Suhardjanto, D. \& Dewi, A. (2011). Pengungkapan Risiko Finansial dan Tata Kelola Perusahaan: Studi Empiris Perbankan Indonesia. Jurnal Keuangan dan Perbankan, 15(1), 105-118.

Al-Maghzom. A., Hussainey, K., \& Aly, D. (2016). Corporate governance and risk disclosure: Evidence from Saudi Arabia. Corporate Ownership and Control, 13(2).

Abraham, S., \& Cox, P. (2007). Analysing the determinants of narrative risk information in UK FTSE 100 annual reports. The British Accounting Review, 39(3), 227-248.

Li, J., Pike, R., \& Haniffa, R. (2008). Intellectual capital disclosure and corporate governance structure in UK firms. Accounting and Business Research, 38(2), 136159.

Ettredge, M., Johnstone, K., Stone, M., \& Wang, Q. (2011). The effects of firm size, corporate governance quality, and bad news on disclosure compliance. Review of Accounting Studies, 16(4), 866-889.

Taliyang, S.M., \& Jusop, M. (2011). Intellectual capital disclosure and corporate governance structure: Evidence in Malaysia.
International Journal of Business and Management, 6(12), 109-117.

Li, J., Mangena, M., \& Pike, R. (2012). The effect of audit committee characteristics on intellectual capital disclosure. The British Accounting Review, 44(2), 98-110.

Allegrini, M., \& Greco, G. (2013). Corporate boards, audit committees, and voluntary disclosure: Evidence from Italian listed companies. Journal of Management and Governance, 17(1), 187-216.

Talpur, S., Lizam, M., \& Zabri, S.M. (2018). Do audit committee structure increases influence the level of voluntary corporate governance disclosures. Property Management, 36(5), 544-561.

Meizaroh \& Lucyanda, J. (2011). Pengaruh Corporate Governance dan Konsentrasi Kepemilikan pada Pengungkapan Enterprise Risk Management. Prosiding. Simposium Nasional Akuntansi XIV.

Buckby, S., Gallery, G., \& Ma, J. (2015). An analysis of risk management disclosures: Australian evidence. Managerial Auditing Journal, 30(8/9), 812-869.

Lopes, P.T., \& Rodrigues, L.L. (2007). Accounting for financial instruments: An analysis of the determinants of disclosure in the Portuguese Stock Exchange. The International Journal of Accounting, 42(1), 25-56.

Oliveira, J., Rodrigues, L.L., \& Craig, R. (2011). Risk-related disclosures by non-finance companies Portuguese 
practices and disclosure characteristics. Managerial Auditing Journal, 26(9), 817-839.

Mokhtar, E.S., \& Mellett, H. (2013). Competition, corporate governance, ownership structure, and risk reporting. Managerial Auditing Journal, 28(9), 838-865.

Abid, A., \& Shaiq, M. (2015). A study of risk disclosures in the annual reports of Pakistani companies: A content analysis. Research Journal of Finance and Accounting, 6(11), 14-24.

Elshandidy, T., \& Neri, R. (2015). Corporate governance, risk disclosure practices, and market liquidity: comparative evidence from the UK and Italy. Corporate Governance: An International Review, 23(4), 331-356.

Carmona, P., Fuentes, C.D., Ruiz, C. (2016). Risk disclosure analysis in the corporate governance annual report using fuzzy-set qualitative comparative analysis. Revista de firm risk disclosures under different firm riskiness, investor-interest, and market conditions: new evidence from Finland. Advances in Accounting, 29(2), 312-331.

Subramaniam, N., McManus, L., \&
Administração de Empresas 56(3), 342-352.

Al-Mutawaa, A., \& Hewaidy, A.M. (2010). Disclosure level and compliance with IFRSs: An empirical investigation of Kuwaiti companies. International Business and Economics Research Journal (IBER), 9(5), 33-50.

Amrin, A. (2019). An emprical study: Charasteristic of business entities and corporate governance on risk disclosure practices. Busines: Theory and Practice, 20(3), 25-49.

Jensen, M.C., \& Meckling, W.H. (1976). Theory of the firm: managerial behavior, agency costs, and ownership structure. Journal of Financial Economics, 3(4), 305360 .

Menon, K., \& Williams, J.D. (1994). The use of audit committees for monitoring. Journal of Accounting and Public Policy, 13(2), 121-139.

Miihkinen, A. (2013). The usefulness of Zhang, J. (2009). Corporate governance, firm characteristics and risk management committee formation in Australian companies. Managerial Auditing Journal, 24(4), 316-339. 